REVIEW

\title{
Understanding injury mechanisms: a key component of preventing injuries in sport
}

\author{
R Bahr, T Krosshaug
}

Br J Sports Med 2005;39:324-329. doi: 10.1136/bjsm.2005.018341

Anterior cruciate ligament $(A C L)$ injuries are a growing cause of concern, as these injuries can have serious consequences for the athlete with a greatly increased risk of early osteoarthrosis. Using specific training programmes, it may be possible to reduce the incidence of knee and ankle injuries. However, it is not known which programme components are the key to preventing knee and ankle injuries or how the exercises work to reduce injury risk. Our ability to design specific prevention programmes, whether through training or other preventive measures, is currently limited by an incomplete understanding of the causes of injuries. A multifactorial approach should be used to account for all the factors involved-that is, the internal and external risk factors as well as the inciting event (the injury mechanism). Although such models have been presented previously, we emphasise the need to use a comprehensive model, which accounts for the events leading to the injury situation (playing situation, player and opponent behaviour), as well as to include a description of whole body and joint biomechanics at the time of injury.

See end of article for authors' affiliations

Correspondence to: Professor Bahr, Oslo Sports Trauma Research Center, Norwegian University of Sport \& Physical Education, Oslo, Norway; roald@nih.no

Accepted 6 March 2005
$\mathrm{R}$ egular physical activity reduces the risk of premature mortality in general and coronary heart disease, hypertension, colon cancer, obesity and diabetes mellitus in particular. ${ }^{12}$ However, sports participation also entails a considerable risk of injury for elite, as well as recreational, athletes. Studies from Scandinavia document that sports injuries constitute 10-19\% of all acute injuries treated in the emergency room, ${ }^{3}{ }^{4}$ and the most common injury types are knee and ankle injuries.

Serious knee injuries, such as those to the anterior cruciate ligament (ACL), are a growing cause for concern. ${ }^{56}$ The highest incidence is seen in adolescents playing pivoting sports such as football, basketball, and team handball, and the incidence is $3-5$ times higher in women than men. ${ }^{78}$ These injuries can have serious consequences for the injured athlete, in terms of not only treatment costs and time lost from sport, but also a greatly increased risk of early osteoarthrosis. ${ }^{9}$ After 10 years, approximately half of all patients display radiological signs of osteoarthrosis, and it is expected that nearly all patients will suffer from osteoarthrosis after 1520 years, regardless of treatment choice. ${ }^{9}$ Recent years have seen an increased interest in research into sports injury prevention, not only related to ACL injuries in pivoting sports, but at least partly spurred on by the concern over ACL injuries in female athletes. In fact, recent studies show that it may be possible to reduce the incidence of knee and ankle injuries in adults ${ }^{10-12}$ and adolescents, ${ }^{13}{ }^{14}$ by using various training programmes. However, the prevention programmes tested are multifaceted and address many aspects that could be related to the risk of injury (agility, balance, strength, awareness of vulnerable knee and ankle positions, playing technique). It is not known which programme component is the key ingredient in preventing knee and ankle injuries or how they work. At least in part, our ability to target and improve current prevention programmes is limited by an incomplete understanding of the causes of injuries. The purpose of this review is to examine current models used to describe the aetiology of sports injuries and to develop a more comprehensive approach to understanding injury causation.

\section{THE SEQUENCE OF PREVENTION: THE EPIDEMIOLOGICAL PERSPECTIVE}

Injury prevention research has been described by van Mechelen et $a l^{15}$ as a four step sequence (fig 1). Firstly, the magnitude of the problem must be identified and described in terms of the incidence and severity of sports injuries. Secondly, the risk factors and injury mechanisms that play a part in the occurrence of sports injuries must be identified. The third step is to introduce measures that are likely to reduce the future risk and/or severity of sports injuries. Such measures should be based on information on the aetiological factors and the injury mechanisms as identified in the second step. Finally, the effect of the measures must be evaluated by repeating the first step, which can be achieved by time trend analysis of injury patterns or, preferably, by means of a randomised clinical trial. ${ }^{3}$

A critical step in the sequence is to establish the causes. This includes obtaining information on why a particular athlete may be at risk in a given situation (risk factors), and how injuries happen (injury mechanisms). Furthermore, a complete understanding of injury causation needs to address the multifactorial nature of sports injuries. As a basis for epidemiological studies, Meeuwisse ${ }^{16}$ therefore developed a model to account for all of the factors involved. As seen in fig 2, although the injury may appear to have been caused by a single inciting event, it may result from a complex interaction between internal and external risk factors. Internal factors such as age, sex, and body composition may 


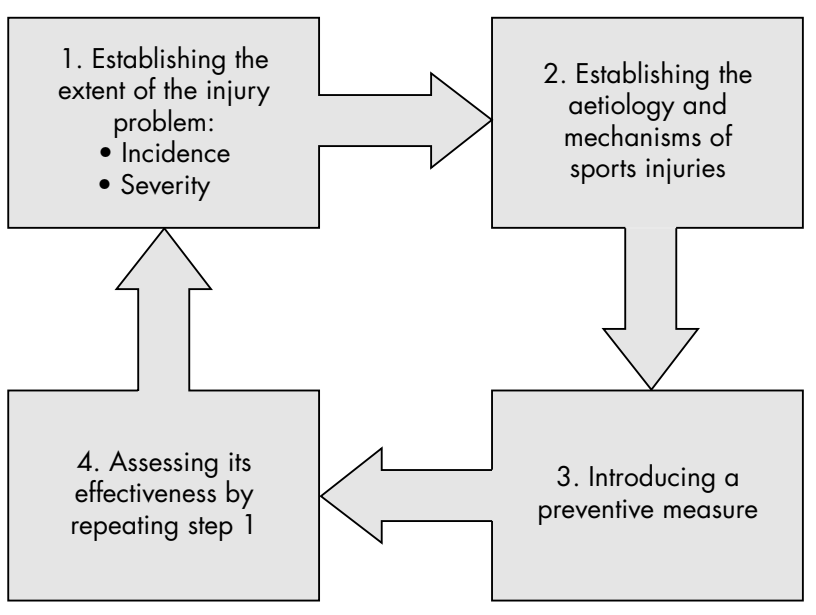

Figure 1 Four step sequence of injury prevention research.

influence the risk of sustaining injuries, predisposing the athlete to injury, and are therefore by definition risk factors. In addition, external factors such as shoe traction and floor friction may modify injury risk, making the athlete even more susceptible to injury. It is the presence of both internal and external risk factors that renders the athlete susceptible to injury, but the mere presence of these risk factors is not sufficient to produce injury. The sum of these risk factors and the interaction between them "prepares" the athlete for an injury to occur in a given situation. Meeuwisse describes the inciting event as the final link in the chain that causes an injury, and such events are regarded as necessary causes. He also states that such an inciting event is usually directly associated with the onset of injury.

As an example, Olsen $e t a l^{17}$ recently showed that there is an increased risk of ACL injuries on high friction floors in handball, but for female players only. This indicates that there is an interaction between sex (internal risk factor) and floor friction (external risk factor) in injury risk, which suggests that there may be a difference in the characteristics of the inciting event between sexes, as well. Perhaps there are differences between male and female players in how they cut and land, which puts the female knee in a vulnerable situation when shoe-floor friction is high. In fact, Hewett et $a l^{18}$ recently showed, in a prospective cohort study, that valgus loading predicted ACL injury in a group of 205 female athletes participating in soccer, basketball, and volleyball. These examples illustrate the need to use a model that accounts for all of these factors at the same time, and not only examine the biomechanics associated with injury or the individual or external risk factors in isolation.

\section{DESCRIBING THE INCITING EVENT: THE BIOMECHANICAL PERSPECTIVE}

Therefore a precise description of the inciting event is a key component to understanding the causes of any particular injury type in sports. The term "injury mechanism" is widely used in medical literature to describe the inciting event in biomechanical terms, but its meaning is not well defined. Whiting and Zernicke ${ }^{19}$ defined this term as "the fundamental physical process responsible for a given action, reaction or result". In another biomechanical perspective, injury is "equivalent to the failure of a machine or structure". ${ }^{20}$

In a basic biomechanical model that takes tissue properties as well as load characteristics into account, injury results from a transfer of energy to the tissue. ${ }^{20}{ }^{21}$ The mechanical properties of human tissue, such as stiffness (stress-strain relation) and ultimate strength, govern how the body responds to physical loads. They differ for each tissue and are dependent on the nature and type of load, its rate, the frequency of load repetition, the magnitude of energy transfer, and intrinsic factors such as age, sex, and physical condition. In this model, it is the relation between load and load tolerance that determines the injury outcome of an event. The key point to consider with regard to biomechanical factors is that they must explain how the event either resulted in a mechanical load in excess of that tolerated under normal circumstances or reduced the tolerance levels to a point at which a normal mechanical load cannot be tolerated. ${ }^{21}$

When comparing the biomechanical model with Meeuwisse's epidemiological model, load and load tolerance can be influenced in different ways by the main elements of the epidemiological model: internal risk factors, external risk factors, and the incident event. Although all of the three elements influence load, load tolerance is mainly determined by the internal risk factors. For instance, important determinants for load tolerance, such as the material properties and size of a ligament, are influenced by age, sex, body size, and training background. The same factors can also influence load-for example, a large male footballer generates higher ligament loads than a small female gymnast performing the same task. External risk factors also influence load; protective equipment such as a helmets attenuate loads, whereas training on a hard surface increases load. In the same way, the inciting event clearly determines the load.

McIntosh $^{21}$ has recently described a more complex biomechanically focused model of injury causation to account for additional factors that may influence the interplay between load and load tolerance (positively or negatively), such as behaviour/attitudes, training, skills, equipment, coaching, other competitors, and the environment. One of

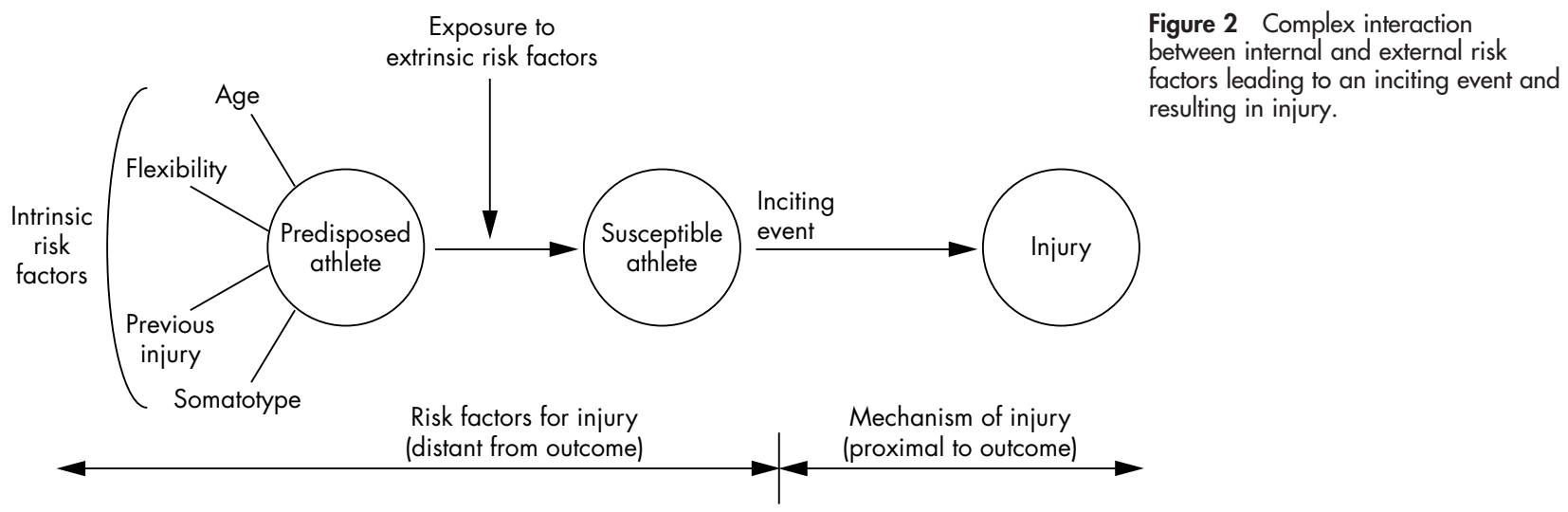

Figure 2 Complex interaction between internal and external risk factors leading to an inciting event and resulting in injury. 
Table 1 Categories of injury mechanism descriptions with examples of elements and descriptions

\begin{tabular}{|c|c|c|c|c|c|}
\hline \multirow[b]{2}{*}{ Category } & \multirow[b]{2}{*}{ Elements } & \multicolumn{4}{|c|}{ Examples of factors describing the injury mechanism } \\
\hline & & $\begin{array}{l}\text { Non-contact } \mathrm{ACL} \\
\text { injury in basketball }\end{array}$ & $\begin{array}{l}\text { ACL injury in a mogul } \\
\text { skiing jump landing }\end{array}$ & $\begin{array}{l}\text { Knock-out in } \\
\text { boxing }\end{array}$ & $\begin{array}{l}\text { Lower leg stress } \\
\text { fracture in football }\end{array}$ \\
\hline \multirow[t]{5}{*}{$\begin{array}{l}\text { Playing (sports) } \\
\text { situation }\end{array}$} & Team action & Fast break & Course steepness & Uppercut, hook & $\begin{array}{l}\text { Exposure to matches } \\
\text { and training (total load) }\end{array}$ \\
\hline & $\begin{array}{l}\text { Skill performed before, } \\
\text { and at, the point of injury }\end{array}$ & Zone defence & $\begin{array}{l}\text { Jump elements (e.g. } \\
\text { twist, helicopter) }\end{array}$ & Counterattack & $\begin{array}{l}\text { Midfielder with } \\
\text { defensive and offensive } \\
\text { tasks (i.e. many runs in } \\
\text { matches/training) }\end{array}$ \\
\hline & $\begin{array}{l}\text { Court position } \\
\text { Player position }\end{array}$ & $\begin{array}{l}\text { Charging } \\
\text { Cutting }\end{array}$ & Jump height \& length & $\begin{array}{l}\text { Foot work } \\
\text { Forced into the } \\
\text { corner/to the ropes }\end{array}$ & $\begin{array}{l}\text { Hard working team } \\
\text { Frequency of duels }\end{array}$ \\
\hline & Ball handling & Setting up for a shot & & $\begin{array}{l}\text { Ring-side referee } \\
\text { decision }\end{array}$ & \\
\hline & & $\begin{array}{l}\text { Defensive rebound } \\
\text { Man to man defence }\end{array}$ & & Inter-boxer distance & \\
\hline \multirow[t]{3}{*}{$\begin{array}{l}\text { Athlete/opponent } \\
\text { behaviour }\end{array}$} & Player performance & Effort & $\begin{array}{l}\text { Rhythm and balance } \\
\text { before the jump }\end{array}$ & Awareness & Effort \\
\hline & Opponent interaction & Disturbance by opponent & Concentration & Aggressiveness & Toe/heel runner \\
\hline & Player attention & $\begin{array}{l}\text { Intention } \\
\text { Foot firmly fixed to the floor } \\
\text { Intention } \\
\text { Technical foul }\end{array}$ & $\begin{array}{l}\text { Balance } \\
\text { Boot binding release } \\
\text { Visual control } \\
\text { Jumping technique } \\
\text { Over-rotation } \\
\text { Falling technique }\end{array}$ & $\begin{array}{l}\text { Punching power } \\
\text { Punching speed } \\
\text { Balance }\end{array}$ & $\begin{array}{l}\text { Jumping technique } \\
\text { Duel technique }\end{array}$ \\
\hline \multirow[t]{4}{*}{$\begin{array}{l}\text { Whole body } \\
\text { biomechanics }\end{array}$} & $\begin{array}{l}\text { Coarse description, } \\
\text { often static, of whole body } \\
\text { kinematics and kinetics }\end{array}$ & Sideways translation & $\begin{array}{l}\text { Linear and angular } \\
\text { momentum }\end{array}$ & $\begin{array}{l}\text { Centre of mass } \\
\text { velocity }\end{array}$ & Stride length \\
\hline & & $\begin{array}{l}\text { Rotation of the body } \\
\text { around the fixed foot }\end{array}$ & Energy absorption & Punching force & Stride frequency \\
\hline & & $\begin{array}{l}\text { Speed at impact } \\
\text { Foot in front of centre of } \\
\text { mass }\end{array}$ & Centre of mass to the rear & $\begin{array}{l}\text { Punching direction } \\
\text { Weight distribution } \\
\text { on the legs }\end{array}$ & $\begin{array}{l}\text { Vertical excursion } \\
\text { Ground reaction forces }\end{array}$ \\
\hline & & & & & Knee flexion angle \\
\hline \multirow{3}{*}{$\begin{array}{l}\text { Joint/tissue } \\
\text { biomechanics }\end{array}$} & Detailed description of joint/ & Valgus moment & Shear forces & Energy transfer & Bending moment \\
\hline & & $\begin{array}{l}\text { Pivot shift of the tibia } \\
\text { relative to the femur }\end{array}$ & Anterior drawer & Head acceleration & Shear forces \\
\hline & & Notch impingement & $\begin{array}{l}\text { Intercondylar lift off, } \\
\text { loading rate }\end{array}$ & $\begin{array}{l}\text { Pressure distribution } \\
\text { and localisation }\end{array}$ & Surface/shoe dynamics \\
\hline
\end{tabular}

the purposes of this model is to describe how load and load tolerance and hence injury risk can change as a result of changes in such factors through interventions. For example, a helmet will attenuate impact energy, thereby reducing the head impact force, and skills training may enable someone to maintain their balance over the weight bearing knee, thus reducing knee loads in the frontal and transverse planes. Improved fitness may protect the tissue against injury through the effects of training on its material properties, but can also result in higher forces being applied to the tissue. If a tennis player through strength, fitness, or skill training develops a faster serve, this can result in a higher load on his/ her shoulder, as well as for the opponent.

These models can also be used to account for risk homoeostasis (risk compensation), changes in behaviour resulting from the introduction of a safety measure. For example, a skier wearing a helmet may take greater risks, such as skiing faster or more aggressively, on more difficult runs, through trees, or off piste. ${ }^{22}$ Thus the end result of introducing a preventive measure may be no change, or even an increase in injury risk, and the need to account for such unwanted effects when introducing protective equipment has recently been emphasised by Hagel and Meeuwisse. ${ }^{22}$

\section{DEFINING "INJURY MECHANISMS"}

Regardless of whether a biomechanical or epidemiological model is used to describe the interaction between the different causative factors, a precise description of the inciting event is critical. The ultimate goal is to use this information to develop specific preventive measures for a specific injury type, perhaps even in a specific sport. To this end, different ways of classifying injury mechanisms have been proposed in the literature. The Committee on Trauma Research classifies causal mechanisms into: (a) crushing deformation; $(b)$ impulsive impact; $(c)$ skeletal acceleration; (d) energy absorption; (e) extent and rate of tissue deformation. ${ }^{23}$ Another source ${ }^{24}$ proposes seven basic mechanisms of injury: (a) contact of impact; $(b)$ dynamic overload; (c) overuse; (d) structural vulnerability; $(e)$ inflexibility; $(f)$ muscle imbalance; $(g)$ rapid growth. However, although these definitions may make sense from a mechanical perspective and be helpful in other areas of trauma research, we would argue that neither of these systems is particularly helpful if the objective is to identify modifiable causes with a potential for intervention in sports injuries.

If we were to describe a situation where a basketball player sustained an ACL injury, one report might be that the injury was caused by "an attacker planting and cutting to set up for a shot". This description includes aspects of the playing situation and skill performed when injured. In addition, the explanation could add that "the incident occurred to a powerful attacker, who was pushed just as she was trying to pass the opponent in a maximal effort", which includes aspects of athlete characteristics and behaviour, as well as opponent behaviour. Another description, with more emphasis on the biomechanical causes of the injury, might be that "the injury occurred as a result of a rapid sideways translation on a high friction surface, rotating while his foot remained firmly planted on the floor." A more detailed biomechanical description could be that "the injury occurred 


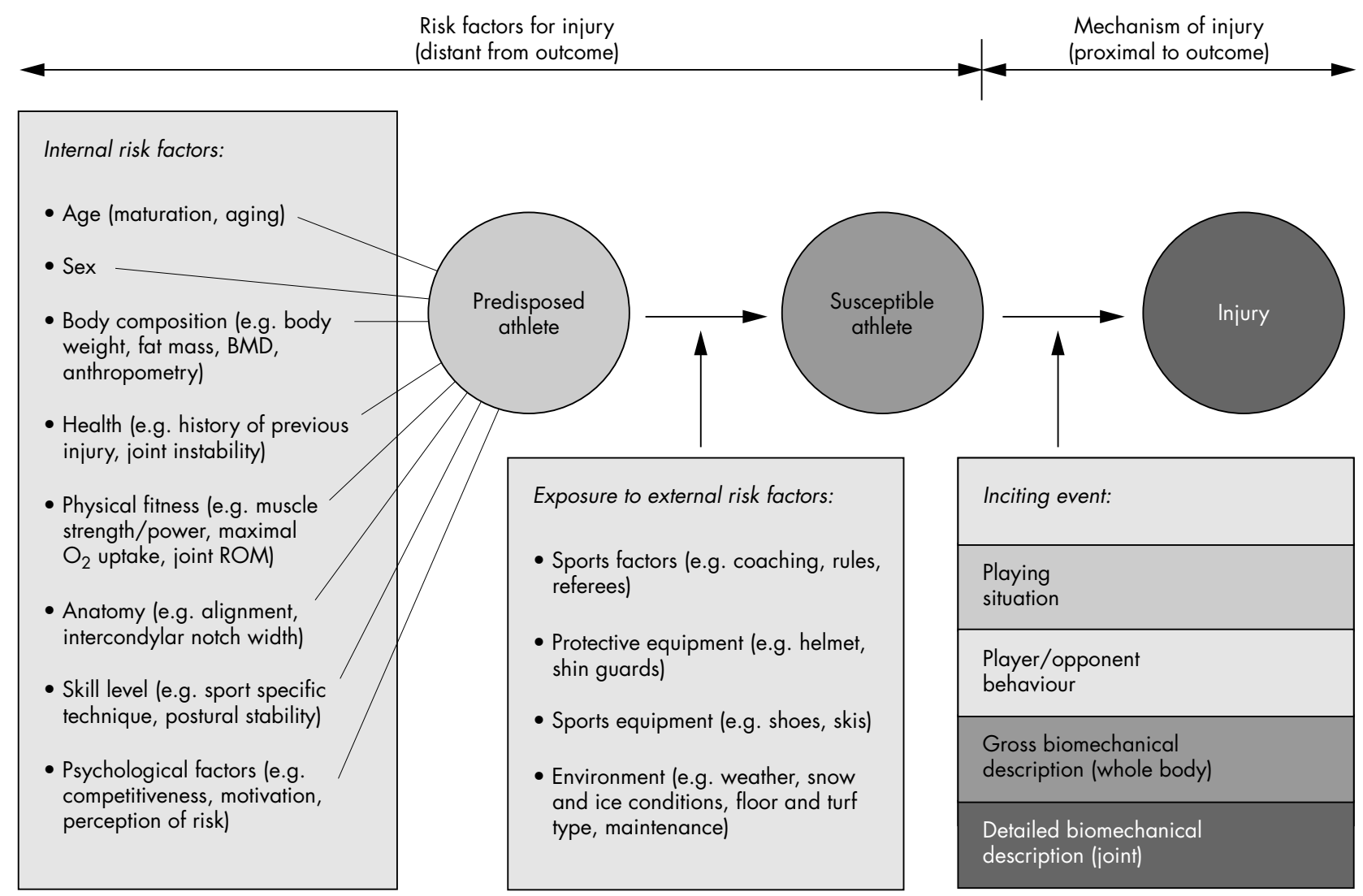

Figure 3 Comprehensive model for injury causation. BMD, Body mass density; ROM, range of motion.

as a result of large external valgus moment and external rotation moment in combination with a translatory shift of the tibia relative to the femur." In other words, the description could include information ranging from the playing situation, player and opponent behaviour, to a more or less detailed biomechanical description of joint motion and loads.

An examination of the literature on sports injuries to see how the term "injury mechanism" is used to understand the mechanisms for ACL injuries shows that biomechanically oriented descriptions dominate, although to a different level of detail. Some studies only provide simple characteristics such as "contact/non-contact injuries"4 or "jumping/nonjumping injuries". ${ }^{25}$ Others use terms like "side-step cutting manoeuvres", "tackle" or "long shot", 26 "spiking" or "blocking", 27 "phantom foot-mechanism" ${ }^{28}$ - descriptions that are related to a specific sport (European team handball, volleyball, and alpine skiing respectively). However, most of the more detailed studies use different biomechanical descriptors to depict the mechanism of injury. The level of detail varies here as well—for example, "deceleration injury" (describes whole body acceleration), ${ }^{29}$ "valgus torque" (describes knee kinetics), "anterior drawer" (describes the relative translation between femur and tibia), ${ }^{31}$ "quadriceps drawer" (describes the relative translation between femur and tibia as the result of quadriceps activation),,$^{32}$ and "intercondylar lift off" (kinematic description of the result from, for example, a valgus or varus load). ${ }^{33}$

It may be argued that, ultimately, the factors causing a joint injury are the loads that act on the joint (contact forces, ligament forces, and muscle forces), resulting from the external forces acting on the body and the internal forces and moments acting within the body. Therefore it is tempting to conclude that a detailed biomechanical description of these factors is the goal, and that this information is more important than a description of the playing situation. This may be a premature conclusion. We would argue that in many cases it is necessary to expand the traditional biomechanical approach to describing the inciting event if the objective is to prevent injuries. For example, an ankle sprain in football could be described as resulting from an inversion injury, a combined supination-internal rotation moment in plantar flexion that causes excessive loads to the anterior talofibular and calcaneofibular ligaments. ${ }^{34}$ However, if the injury results from illegal tackles from the side or behind, ${ }^{35}$ this information may be more relevant in a prevention perspective than a precise biomechanical description of ligament loading patterns. If severe sanctions to the player and team were introduced for such behaviour, this should result in fewer injuries.

Therefore we suggest that a full description of the mechanisms for a particular injury type in a given sport should include information on different levels. The description of the inciting event could be grouped into four categories, as shown in table 1 . Hence, the term "injury mechanism" is here used to describe: (a) vital aspects of the playing (sports) situation-that is, the situation described from a sports specific point of view; $(b)$ athlete and opponent behaviour-that is, a qualitative description of the athlete's action and interaction with the opponent; (c) gross biomechanical characteristics-that is, a description of whole body biomechanics; $(d)$ detailed biomechanical characteristics - that is, a description of joint/tissue biomechanics.

To enable comparisons between studies, it is also important to agree on which elements to describe for each injury type and sport, and to develop clear definitions and terminology for these descriptions. Even when considering 
What is known on this topic

- Knowledge on risk factors and injury mechanisms is necessary to develop effective preventive measures for sports injuries.

- A multifactorial approach is required to account for all the factors involved-that is, the internal and external risk factors as well as the inciting event.

such a key issue as the need to distinguish between contact and non-contact mechanisms for ACL injuries, there is no universally accepted definition for these terms. ${ }^{36}$ For the sports related component of the injury mechanism description, the specific terminology, definitions, and analytical methods used to analyse and describe sports performance can represent useful tools in injury analysis, as well. For example, Andersen $e a^{37}$ have adapted the analytical methods used to describe football performance to analyse injury situations from match videos.

It should also be noted that-especially for overuse injuries-the inciting event can sometimes be distant from the outcome. For example, for a stress fracture in a long distance runner, the inciting event is not usually the single training session when pain became evident, but the training and competition programme he or she has followed over the previous weeks or months. Until a complete description is available which includes information on all causative factors, it may be difficult to predict which factors may be modifiable through intervention.

\section{A COMPREHENSIVE INJURY CAUSATION MODEL}

On the basis of a more complete approach to the description of the injury mechanisms, it is possible to develop a comprehensive model for injury causation (fig 3). This model is based on the epidemiological model of Meeuwisse, ${ }^{16}$ and includes not only a biomechanical perspective as described by McIntosh, ${ }^{21}$ but also focuses on the characteristics of the sport in question.

In this model, intrinsic and extrinsic risk factors can affect load and load tolerance. For instance, the intercondylar notch width has been discussed as a risk factor for non-contact ACL injuries in many studies. ${ }^{38-40}$ There are two major theories on how the notch width could influence injury rates. One is a possible association between notch width and ligament width (hence strength) - that is, ligament load tolerance as an intrinsic risk factor. The other hypothesis involves the interaction between an internal risk factor (that a narrow intercondylar notch can lead to impingement of the ACL on the medial aspect of the femoral condyle) and the injury mechanism (that this may be more likely to occur when the knee is loaded in valgus and external rotation of the tibia). As mentioned above, it is even possible that this is more likely to occur on high friction floors (external risk factor) or to athletes with suboptimal neuromuscular control (internal risk factor).

The model can be used to study the interaction between different factors causing injury and address the potential for prevention-for example, for ankle sprains in volleyball or football. In both sports, the risk of an ankle sprain is 4-5 times higher if there is a history of previous injury to the same ankle (internal risk factor), ${ }^{41}{ }^{42}$ mainly because of reduced neuromuscular function. ${ }^{43-45}$ Ankle sprains in volleyball mainly occur at the net when a player lands on the foot of an opponent or a teammate after blocking or attacking (injury mechanism). ${ }^{46}$ Ankle sprains in football mainly occur from late tackles from the side, often with impact by
What this study adds

- It is necessary to expand the traditional biomechanical approach to a description of the inciting event if the objective is to prevent injuries.

- A complete description of the mechanisms for a particular injury type in a given sport needs to account for the events leading to the injury situation (playing situation, player and opponent behaviour), as well as to include a description of whole body and joint biomechanics leading up to, and at the time of, injury.

- To address the potential for prevention, the information on injury mechanism must be considered in a model that also considers how internal and external risk factors can modify injury risk.

an opponent on the medial aspect of the leg just before or at foot strike, resulting in a laterally directed force (injury mechanism). ${ }^{35}$ These studies show that a significant proportion of ankle injuries are contact injuries resulting from a player landing on another player's foot (volleyball) or a medial blow to the ankle or lower leg (football), mechanisms where neither balance training nor ankle bracing would be expected to have a protective effect. However, it may be that the direct contact is not what causes the ligaments to tear, but merely serves to put the ankle in a vulnerable position when landing or running, especially in players with reduced neuromuscular control. Thus, on the basis of this, it may be hypothesised that increased neuromuscular control through training or bracing could help the player to position the foot correctly before putting weight on the ankle. Studies have shown that ankle sprains can be prevented through balance training and bracing in volleyball and football. In fact, the protective effects of taping and bracing have been persuasively shown in football, ${ }^{48} 49$ although only for players with previous ankle injury. In addition, in players with a history of previous injury, a balance training programme appears to reduce the risk of reinjury to the same level as healthy ankles in football ${ }^{49}$ and volleyball players. ${ }^{4650}$ These findings illustrate how information on risk factors and injury mechanisms can be used to develop targeted prevention methods. This approach should be used for each specific injury type in a given sport.

\section{CONCLUSIONS}

A precise description of the inciting event is a key component to understanding the causes of any particular injury type in a given sport. It is necessary to expand the traditional biomechanical approach to describing the inciting event, if the objective is to prevent injuries. A complete description of the mechanisms for a particular injury type in a given sport needs to account for the events leading to the injury situation (playing situation, player and opponent behaviour), as well as to include a description of whole body and joint biomechanics at the time of injury. To address the potential for prevention, the information on injury mechanism must be considered in a model that also considers how internal and external risk factors can modify injury risk.

\section{Authors' affiliations}

R Bahr, T Krosshaug, Oslo Sports Trauma Research Center, Norwegian University of Sport \& Physical Education, Oslo, Norway

Competing interests: none declared 


\section{REFERENCES}

1 Pate RR, Pratt M, Blair SN, et al. Physical activity and public health. A recommendation from the Centers for Disease Control and Prevention and the American College of Sports Medicine [see comments]. JAMA 1995:273:402-7.

2 Fletcher GF, Balady G, Blair SN, et al. Statement on exercise: benefits and recommendations for physical activity programs for all Americans. A statement for health professionals by the Committee on Exercise and Cardiac Rehabilitation of the Council on Clinical Cardiology, American Heart Association. Circulation 1996;94:857-62.

3 Bahr R, Kannus P, van Mechelen W. Epidemiology and prevention of sports injuries. In: Kjaer M, Krogsgaard M, Magnusson SP, et al, eds. Textbook of sports medicine. Basic science and clinical aspects of sports injury and physical activity. Oxford: Blackwell Science, 2003:299-314.

4 Arendt E, Dick R. Knee injury patterns among men and women in collegiate basketball and soccer. NCAA data and review of literature. Am J Sports Med 1995;23:694-701.

5 Ytterstad B. The Harstad injury prevention study: the epidemiology of sports injuries. An 8 year study. BrJ Sports Med 1996;30:64-8.

6 de Loes M. Medical treatment and costs of sports-related injuries in a total population. Int J Sports Med 1990;11:66-72.

7 Myklebust G, Maehlum S, Engebretsen L, et al. Registration of cruciate ligament injuries in Norwegian top level team handball. A prospective study covering two seasons. Scand J Med Sci Sports 1997;7:289-92.

8 Myklebust G, Maehlum S, Holm I, et al. A prospective cohort study of anterior cruciate ligament injuries in elite Norwegian team handball. Scand J Med Sc Sports 1998;8:149-53.

9 Myklebust G, Bahr R. Return to play guidelines after anterior cruciate ligament surgery. Br J Sports Med 2005;39:127-31.

10 Myklebust G, Engebretsen L, Braekken IH, et al. Prevention of anterior cruciate ligament injuries in female team handball players: a prospective intervention study over three seasons. Clin J Sport Med 2003;13:71-8.

11 Wedderkopp N, Kaltoft M, Lundgaard B, et al. Prevention of injuries in young female players in European team handball. A prospective intervention study. Scand J Med Sci Sports 1999:9:41-7.

12 Hewett TE, Lindenfeld TN, Riccobene JV, et al. The effect of neuromuscular training on the incidence of knee injury in female athletes. A prospective study. Am J Sports Med 1999;27:699-706.

13 Heidt RS Jr, Sweeterman LM, Carlonas RL, et al. Avoidance of soccer injuries with preseason conditioning. Am J Sports Med 2000;28:659-62.

14 Junge A, Rosch D, Peterson L, et al. Prevention of soccer injuries: a prospective intervention study in youth amateur players. Am J Sports Med 2002;30:652-9.

15 van Mechelen W, Hobil H, Kemper HC. Incidence, severity, aetiology and prevention of sports injuries. A review of concepts. Sports Med 1992;14:82-99.

16 Meeuwisse WH. Assessing causation in sport injury: a multifactorial model. Clin J Sport Med 1994:4:166-70.

17 Olsen OE, Myklebust G, Engebretsen L, et al. Relationship between floor type and risk of ACL injury in team handball. Scand J Med Sci Sports 2003; 13:299-304.

18 Hewett TE, Myer GD, Ford KR, et al. Biomechanical measures of neuromuscular control and valgus loading of the knee predict anterior cruciate ligament injury risk in female athletes. A prospective study. Am J Sports Med 2005;33:1-9.

19 Whiting WC, Zernicke RF. Biomechanics of musculoskeletal injury. Champaign, IL: Human Kinetics, 1998.

20 Fung Y. Accidental injury: biomechanics and prevention. New York: SpringerVerlag, 1993.

21 Mclntosh AS. Risk compensation, motivation, injuries, and biomechanics in competitive sport. Br J Sports Med 2005;39:2-3.

22 Hagel B, Meeuwisse W. Risk compensation: a "side effect" of sport injury prevention? Clin J Sport Med 2004;14:193-6.

23 Committee on Trauma Research. Injury in America: a continuing public health problem. Washington, DC: National Academy press, 1985.

24 Seering WP, Piziali RL, Nagel DA, et al. The function of the primary ligaments of the knee in varus-valgus and axial rotation. J Biomech 1980;13:785-94.
25 Paul JJ, Spindler KP, Andrish JT, et al. Jumping versus nonjumping anterior cruciate ligament injuries: a comparison of pathology. Clin I Sport Med 2003; 13:1-5

26 Strand T, Tvedte R, Engebretsen L, et al. [Anterior cruciate ligament injuries in handball playing. Mechanisms and incidence of injuries]. Tidsskr Nor Laegeforen 1990; 1 10:2222-5.

27 Ferretti A, Papandrea P, Conteduca F, et al. Knee ligament injuries in volleyball players. Am J Sports Med 1992;20:203-7.

28 Ettlinger CF, Johnson RJ, Shealy JE. A method to help reduce the risk of serious knee sprains incurred in alpine skiing. Am J Sports Med 1995;23:531-7.

29 Boden BP, Dean GS, Feagin JA Jr, et al. Mechanisms of anterior cruciate ligament injury. Orthopedics 2000;23:573-8.

30 McLean SG, Huang X, Su A, et al. Sagittal plane biomechanics cannot injure the $\mathrm{ACL}$ during sidestep cutting. Clin Biomech (Bristol, Avon) 2004; 19:828-38.

31 Geyer M, Wirth CJ. [A new mechanism of injury of the anterior cruciate ligament]. Unfallchirurg 1991;94:69-72.

32 DeMorat G, Weinhold P, Blackburn T, et al. Aggressive quadriceps loading can induce noncontact anterior cruciate ligament injury. Am J Sports Med 2004;32:477-83.

33 Hewett TE, Stroupe AL, Nance TA, et al. Plyometric training in female athletes. Decreased impact forces and increased hamstring torques. Am J Sports Med 1996;24:765-73.

34 Bahr R, Pena F, Shine J, et al. Ligament force and joint motion in the intact ankle: a cadaveric study. Knee Surg Sports Traumatol Arthrosc 1998:1 15-21.

35 Andersen TE, Floerenes TW, Arnason A, et al. Video analysis of the mechanisms for ankle injuries in football. Am J Sports Med 2004:32:69S-79S.

36 Krosshaug T, Andersen TE, Olsen O-E, et al. Research approaches to describe the mechanisms of injuries in sports: limitations and possibilities. Br J Sports Med 2005;39.

37 Andersen TE, Larsen $O$, Tenga A, et al. Football incident analysis: a new video based method to describe injury mechanisms in professional football. Br J Sports Med 2003;37:226-32.

38 Souryal TO, Freeman TR. Intercondylar notch size and anterior cruciate ligament injuries in athletes. A prospective study. Am J Sports Med 1993;21:535-9.

39 Lund-Hanssen H, Gannon J, Engebretsen L, et al. Intercondylar notch width and the risk for anterior cruciate ligament rupture. A case-control study in 46 female handball players. Acta Orthop Scand 1994;65:529-32.

40 LaPrade RF, Burnett QM. Femoral intercondylar notch stenosis and correlation to anterior cruciate ligament injuries. A prospective study. Am J Sports Med 1994;22:198-202.

41 Bahr R, Bahr IA. Incidence of acute volleyball injuries: a prospective cohort study of injury mechanisms and risk factors. Scand J Med Sci Sports 1997;7:166-71.

42 Arnason A, Sigurdsson SB, Gudmundsson A, et al. Risk factors for injuries in football. Am J Sports Med 2004;32:5S-16S

43 Karlsson J, Peterson L, Andreasson G, et al. The unstable ankle: a combined EMG and biomechanical modeling study. Int J Sport Biomech 1992;8:129-44.

44 Konradsen L, Ravn JB. Prolonged peroneal reaction time in ankle instability Int J Sports Med 1991;12:290-2.

45 Tropp H, Odenrick P, Gillquist J. Stabilometry recordings in functional and mechanical instability of the ankle joint. Int J Sports Med 1985;6:180-2.

46 Bahr R, Lian O, Bahr IA. A twofold reduction in the incidence of acute ankle sprains in volleyball after the introduction of an injury prevention program: a prospective cohort study. Scand J Med Sci Sports 1997;7:172-7.

47 Bahr R, Lian $\varnothing$, Karlsen R, et al. Incidence and mechanisms of acute ankle inversion injuries in volleyball: a retrospective cohort study. Am J Sports Med 1994;22:601-4.

48 Surve I, Schwellnus MP, Noakes T, et al. A fivefold reduction in the incidence of recurrent ankle sprains in soccer players using the Sport-Stirrup orthosis. Am J Sports Med 1994;22:601-6.

49 Tropp H, Askling C, Gillquist J. Prevention of ankle sprains. Am J Sports Med 1985;13:259-62.

50 Verhagen $E$, van der Beek AJ, Twisk J, et al. The effect of a proprioceptive balance board training program for the prevention of ankle sprains: a prospective controlled trial. Am J Sports Med 2004;32:1385-93. 